\title{
Phenomenology Study of High School Students' Experiences Who Do Suicidal-Attempt in Malang City, Indonesia
}

\author{
Yusfina Himayanti ${ }^{1}$, Retty Ratnawati ${ }^{2}$, Laily Yuliatun ${ }^{3}$, Heni Dwi Windarwati ${ }^{4}$ \\ ${ }^{1}$ Master Program of Nursing, Faculty of Medicine, University of Brawijaya, Malang, \\ Indonesia \\ ${ }^{2,3,4}$ Faculty of Medicine, University of Brawijaya, Malang, Indonesia \\ Email: yusfinahimayanti@gmail.com
}

\begin{abstract}
The objective of this study is to explore the experiences of high school students who are committing suicide in Malang, Indonesia. The study was qualitative research with an interpretive phenomenological approach and data analysis using IPA (Interpretative Phenomenological Analysis). Themes generated based on the results of the study include disappointment in the family as the basis of adolescent suicide, abuse from school friends triggers adolescents to think of suicide, and adolescents conduct suicide attempts spontaneously without planning. The results of this study indicate that many of the problems teenagers feel and think that trigger up causing teenagers to attempt suicide. The results of this study can also help us to better understand suicide attempts from the point of view of adolescents.
\end{abstract}

Keywords: Experience, Teenagers, Suicide Attempts.

\section{A. INTRODUCTION}

Mental health problems in adolescents are a global phenomenon (WHO, 2018). Seven mental health problems are found in teenagers. First is emotional disorders such as anger, frustration and depression (Nanyakarra, 2013). Depression in adolescents is the ninth cause of mental health problems in adolescents with the effects of withdrawal, loneliness and suicide. The second is behavior disorder in the form of hyperactivity, lack of attention and destructive behavior which is the sixth leading cause of disease burden in adolescents. Third is eating disorders in the form of eating restrictions in connection with the shape and weight that are side by side with the problems of depression, anxiety and substance abuse. Fourth is the psychosis that occurs in late adolescents, affecting the stigma and human rights violations of adolescents. Fifth is suicide. Suicide in adolescents occupies the third cause of death in adolescents. The sixth is risk taking behavior such as substance abuse and free sex that occurs in 13.6\% of adolescents in 2016. The seventh is violence against adolescents and bullying which ranks second in death in adolescents.

Impacts that can be caused by mental health problems include a decline in social relationships, fulfillment of low psychological well-being and difficulty interacting in the context of their environment in adulthood. Another impact is the emergence of feelings of anxiety about school or friendship, or experiencing a period 
of depression after the death of a close person or family member. A serious consequence of mental health problems in adolescents is life threat. Depression, mental health disorders and drug abuse in adolescents are the main risk factors for suicide (Stuart, 2014).

Suicide is a behavior that must be avoided. Suicide is a conscious effort and aims to end life, the individual consciously desires and seeks to carry out his desire to die (Muhith, 2015). The research of (Farhangdoost, 2010) declaring suicide is a practical expression where someone intentionally and consciously ends one's own life. So suicide is self-injuring behavior to end life.

According to (Stuart, 2014), Suicidal risk factors in adolescents include psychological factors, family factors, environmental factors, biological factors, previous suicidal behavior and sexual orientation. According to (Cho \& Haslam, 2010) social support tends to have special relevance for suicide prevention. Various risk factors for adolescent suicide are related to one another. The research of (Ibrahim, Amit, \& Suen, 2014) in Malaysia there is a significant relationship between psychological factors, namely depression, anxiety and stress with the idea of suicide. The study result of (Lee et al., 2013) showed that the risk of suicide in adolescent boys was significantly associated with a history of death of a suicide father and conversely adolescent girls were significantly associated with a history of maternal suicide deaths.

Another factor is the social environment, in the research of (Pisani et al., 2013) obtained a sample of students with suicidal ideas as much as $13.9 \%$ considering suicide in the last 12 months. Students with suicidal ideas more often express suicidal ideas to peers $(54 \%)$ than older people $(23 \%)$. Therefore environmental factors are important in adolescent suicide.

The next factor is sexual orientation. The average suicide attempt occurs in a group of gay, lesbian and bisexual teenagers (Stuart, 2014). This is in line with the results of the study (O'Donnell, Meyer, \& Schwartz, 2011) mentioned an increased risk of suicide ideas and attempts in Italy between lesbians, gays and bisexuals. No less important factor is the history of previous suicide attempts. The first two years after a suicide attempt is a period of high risk (Stuart, 2014).

The study result of (Billiocta, Sani, \& Jaya, 2015) in Indonesia reported that there were five teenagers who committed suicide because of problems with close friends, in Singaraja, Bali a teenager (17 years old) jumped from the 3rd floor of a school building. A teenager (16 years old) in Bangli drank insecticide, a grade 1 vocational school student in Widodaren, Ngawi swallowed cold medicine to overdose, two of which occurred in Riau province where a teenager (18 years old) in Pelalawan drank poison and a girl in Rengat tried jump from a height.

Suicide in Malang City in 2019 recorded 16 cases, with 1 suicide incident involving adolescents, this number increased compared to 2018 ago with a case of 11 people (Malang Police), this is very contrary to the majority of the population of Malang City is a tribe Javanese and Muslim where suicide is a behavior that is prohibited both culturally and religiously. 
Based on the results of the detection of mental health in adolescents who are part of a community service research chaired by Heni Dwi Windarwati conducted at SMKN 11 Malang, this phenomenology study is a further development of community service programs through a questionnaire conducted in September 2019 of 869 students found 108 teenagers (12.4\%) showed a high suicide idea and as many as 98 people $(11.3 \%)$ showed a low suicide idea while the rest showed no suicide idea (Windarwati, 2019).

Based on the results of the research, the researchers conducted a preliminary study with in-depth interviews with 11th grade students of SMKN 11 Malang City $\mathrm{Nn}$ "y" revealed that $\mathrm{Nn}$ " $\mathrm{y}$ " experienced many problems including broken parents, friends and girlfriends. Nn "y" said that she wanted to die because no one cared about her, especially the father who often committed violence in the household and in Nn "y", so that the solution to be done when the problem occurred was silence, crying and shut himself in his room, hurting yourself and then banging the head of the wall, repeatedly bruising with the aim of seeking peace but can't be obtained by $\mathrm{Nn}$ "y" which ultimately makes Nn "y" carry out suicide attempts by cutting off the pulse.

Based on research results (Windarwati, 2019), so far the teenagers' perceptions about suicide are unknown, so research needs to be done on the experiences of students conducting suicide attempts in Malang using qualitative research methods with a phenomenological approach.

\section{B. METHOD}

This research was conducted to explore the experience of high school students who carried out suicide attempts in Malang, Indonesia using the phenomenological method. Participants in this study were students in Public Vocational High School of 11 Malang (SMKN 11 Malang) in eleventh grade, aged 14-17 years who were selected based on the results of the detection of mental health in adolescents who were part of a community service study chaired by Henni Dwi Windarwati conducted at SMKN 11 Malang, this Phenomenology Study is a further development of community service program through a questionnaire conducted in September 2019 of 869 students and 108 teenagers (12.4\%) showed high suicide ideas and 98 people $(11.3 \%)$ showed low suicide ideas while the rest showed no suicide idea (Windarwati, 2019). This study has obtained information on ethical eligibility from the Medical Research Ethics Commission of the Faculty of Medicine, University of Brawijaya No. 46/EC/KEPK-S2/02/2020.

The researcher visited SMKN 11 Malang and explained the purpose of the study and to ask for cooperation from the school. Participants were selected through a purposive sampling method, except those who had never attempted suicide and or who refused to participate. In a preliminary study of this study, researchers interviewed 2 students who had attempted suicide. The students and their parents were informed by the researcher about the aims and procedures of the study before giving written consent. They are also told that they can withdraw their participation 
at any time before publishing the results. In presenting the results, each participant was given a code or pseudonym to maintain their anonymity.

Students who will be interviewed have received permission from their parents to be recorded their audio, before the interview conducted. Specific data collection uses the following procedure. First, the researcher explains the procedure before the interview, and confirms either by telephone call or a visit whether the interview will be possible. After setting the date, time, and place of interview with the participant the day before to be interviewed. Second, the researcher makes guide questions for the interview process. Beginning the interview using open-ended questions, starting with requests for introductions, asking for news and just entering general questions such as "can you tell me about the problems you've been experiencing?", What were you thinking about when attempting suicide, how did you feel before attempting suicide, how do you feel after you realize that you have carried out a suicide attempt, how is the response of the closest person after knowing the suicide attempt by parents, friends and neighbors. A total of 5 students were involved in this study, with interviews conducted per person. 45 minutes after this process, the data collected is then transcribed, in the form of a verbatim transcript, nonverbal communication, such as crying, silence, and nodding, also recorded during the interview "as clearly as possible." In addition, a diary about the experiences and feelings of participants during the interview process is written immediately after each interview ra, and included as data in the analysis. Interviews for the data collection process are carried out until no new concepts emerge and the information becomes saturated. The data collection period is from March to April 2020.

Data of study results were analyzed by using IPA (interpretative phenomenological analysis) which consisted of six steps, they were reading and re-reading, initial nothing, developing emergent themes, moving to the next cases and looking for patterns for patterns across cases. The data analysis results from the five participants are related to the experience of high school students who have attempted suicide in Malang, Indonesia.

\section{RESULT AND DISCUSSION}

\section{Disappointment in Parents as the Basis of Teenagers Suicidal Attempts}

Disappointed in the big Indonesian dictionary is discouraged; not satisfied (because his wish was not fulfilled). Context disappointed in this study on special families in the elderly. This theme is formed from two sub-themes, namely, upset at parents who often fight, feel broken because parents are separated.

The first sub theme, upset at parents who often fight. The participant statement expresses as follows:

“... I'm disappointed, I want to think the problems of my parents, but it like a mess, why is everything like this not as good as it used to be, so I'm confused, I want to go out but I don't have money, I want to everything is like used to be, I like to go to hangout with my family like it was"(p1) 
“... it's stuffy ma'am, when my parents get angry, they tell me anything"(p2)

"... the most severe is the problem from parents, ma'am"(p5)

"... my parents are not divorce, ma'am, they just separate with me, just a lot of conflicts, they often fight, there, I really get angry,(p3)

"... yes ma'am, they often fights because of any problems. I'm confused too, ma'am, what should I do ... there is nothing I can do for them" (p4)

Sub-theme 2 feel broken because of parents who separated, it expressed by participant such as:

"... Yes, what should I do, what can I do, it feels ruined, with parents who fight constantly being beaten every day" (p3)

"... their words that make me really sick ma'am, my dad said that I'm not good children, my dad had a lot of money then, and now his money runs out Malang because of me" (p5)

“... no greetings, I'm so sad when I see it"(p1)

"... yesterday, it seems like I feel like there are problems with my family, problems with my friends, right from junior high school, at first I was bullied, it really hurts" (p2)

"... Yes broken home right ... they often fight like that every day and finally ma'am got re-married well since that time I was a bit like that, but yeah what else can I do, I'm confused and sad"(p4)

\section{Harassment from School Friends Triggers Teenage Suicidal Thoughts}

Harassment in a large Indonesian dictionary is to hurt others both physically and psychologically, in the form of verbal, social, or physical violence repeatedly and from time to time, such as calling someone's name with an unpleasant nickname, hitting, pushing, spreading rumors, threaten or undermine. The context of harassment in this study is peers at school. This theme is formed from 2 sub-themes, which are hurt by the abuse of friends at school and resignation to the situation.

Sub theme 2.1 hurt by the harassment of friends at school. Harassment by peers at school raises feelings of hurt, resentment, disappointment, resentment, depression, fear, shame, sadness, discomfort and is threatened by teenagers. This condition affects the feeling of helplessness in defending themselves in the face of harassment (Rigby, 1993). Socially adolescents who experience abuse will isolate themselves, fear of going to school and afraid of contracting with others. The participant statement expresses as follows:

"...if there is a problem, he tells the story to someone else, so the problem is from my friend, not from him, then I am constantly being bullied, ma'am, I don't reply, just let it hurt." (p1)

"...I'm bullied ma'am, I often told that I'm a whore, I have a feeling ma'am and that's what makes me hurt ma'am"(p4)

"...being mocked, when I was in junior high school, ma'am, then I was ostracized, (p3) 
"...being mocked that I'm people with sickness, I never asked me to get sick, I also don't want to have a sickness, then I was laughed at by all my friends, It's so hurt" (p5)

Sub theme 2.2 resigned to harassment. The participant expressions are as follows:

"... I just can't stand ma'am, I was told to keep on doing what they ask ma'am"

"...I feel like a good person like there's no point anymore ma' $\mathrm{am}^{\prime}$

"...they just do whatever they want, yeah, then they tell me like a dog from 7 th grade to 8 th grade ma'am I'm embarrassed " (p3)

“...I was mocked, ma'am, I didn't reply"(p1)

\section{Adolescents Carry Out Spontaneous Suicide Attempts Without Planning}

Spontaneous in the big Indonesian dictionary is necessarily, without thinking, or without premeditated; do something because of impulse, not because of advice and so on. This is different from attempted suicide in adults who do it with careful planning problem. This theme is formed from 2 sub themes including finding a way out and being hurt by the problems they are experiencing.

Sub theme 3.1 find a way out of all problems. Participants' remarks, among others. The participant expressions are as follows:

"...Like I don't have a solution anymore, what should I do? Who else wants to help" (p1)

“... Initially continued spontaneous ma'am "( 2 2)

"... I think to be free from the problems ma'am" (p3)

"...When I want to commit suicide, I don't think ma'am, It comes immediately" (p3)

"... I want to get out of the problem ma'am"(p4)

"... It's like you're not thinking about anything"(p5)

"... Yes, so I don't need to think this problem anymore, I'm tired" (p5)

Sub theme 3.2 hurt with the problem at hand. The participant expressions are as follows:

"... my feeling is ruined, ma'am, with this problem" (p1)

" ... It hurts me to go through all this "(p2)

"... Like the tightness in your chest, then I never told anyone who I am, whoever" (p3)

"... I was desperate, I thought about suicide, ma'am (p4)

"... With all the problems it felt bored, frustrated, ma'am (p5)

Disappointment in parents as the basis of adolescent suicide. The results of this study stated that adolescents have a deep disappointment in parents because of fights committed by parents. The fight or conflict causes adolescents to feel upset, sad and responsible for problems faced by parents, especially problems relating to the economy. If the conflict between parents and adolescents is allowed to drag on it can lead to negative things both for adolescents themselves and in the relationship between themselves and parents. This condition is a stressor condition for 
adolescents who can cause complex problems, whether physical, psychological, social or educational. Among other things can arise various physical complaints that are not clear causes, as well as various problems that have social impacts such as school mals, drug abuse brawl even the worst conditions that have been carried out by all participants in this study is attempted suicide.

Based on the results of this study, all participating families have a history of divorce. The most common effects of parental divorce on adolescents are attitude changes. Fighting every day and getting divorced. Finally triggering teenagers to carry out suicide attempts, this is in line with research Purwati (2010) states that suicide is an attitude to self-harm, because teenagers do not get the complete love from their parents. is the responsibility of parents who are rarely realized. Another disappointment that is the basis of teenage suicide is parental divorce. Adolescent responses after parents divorced in this study showed a sad response. Their parents' divorce carved a painful inner wound for them. With conditions like this they also learn to adjust to the circumstances they are experiencing now. Sadness is the most profound reaction for children when their parents separate. Children will be very confused when their parents' relationships do not go well, especially if they continue to hurt, both physically and vertically (Purwati, 2010).

Another fact says that after the divorce of his parents, the possibility of adolescents will experience psychological effects where one of them is lonely. This is in accordance with the opinion of Wasil (2014) which states that divorce has a psychological impact on children such as: feeling uncomfortable because of losing one of his family members, unstable emotions such as anger, feeling lonely because of the loss of one family member, feeling sad and feeling disappointed towards his family. Another thing also stated by the Choir et al. (2010), states that the group of adolescents who do not live with older people have higher levels of life stress, distress, psychological symptoms and suicidal ideation.

The second theme, namely harassment from school friends triggers adolescents to think of suicide. Harassment or bullying experienced by all participants in this study shows feelings of heartache that are so deep in peers. Harassment or bullying itself can be interpreted as a negative physical or verbal act that shows hostility, thereby causing distress for the victim, repeating within a certain period of time and involving differences in power between the perpetrator and the victim (Masdin, 2013).

The results of research by the international NGO plan and the 2015 International Center for Research on Women show that $84 \%$ of Indonesian children experience school violence. UNICEF data also states that 1 in 3 Indonesian children experience violence. This indicates that every child has the potential to be a perpetrator or victim of aggression that leads to crime. The results of this study show that adolescents who experience bullying (bullying victims) at school by peers triggers them to think and even carry out suicide attempts because they cannot stem feelings of hurt anymore. This is consistent with research by van Geel, Vedder, 
Tanilon (2014) which states $80 \%$ of adolescents have suicidal tendencies related to bullying.

Participants who experienced harassment in this study also expressed sadness, uncomfortable resignation and despair but were helpless in dealing with feelings of depression, anxiety because the perpetrators controlled the victims. This condition has an impact on feeling helpless in defending himself against the perpetrators of bullying (Rigby, 1993). Another study conducted by the Cyberbullying Research Center found that victims of cyber bullying have a higher tendency to commit suicide compared to bullying conducted face to face. This shows that harassment or bullying can occur to anyone, anytime and anywhere even lead to the worst conditions such as the results of this study where adolescents carry out suicide attempts triggered by peer abuse at school.

The third themes is adolescents carry out spontaneous suicide attempts without planning. Participants in this study suggest they carry out a suicide attempt without being planned in advance. Adolescent perception about the cause of adolescent suicide is the inability to solve problems so that individuals choose to die so that the problem is solved. This can be explained by the concept of fight and flight (Douglas 1991), which is when an individual faces a problem that is felt to be threatening then physiologically and psychologically the body provides a mechanism of response to remain in a balanced state. If the individual uses a fight mechanism, the individual will try to solve the problem, but if the individual chooses to fly, then the problem is not solved and one way to escape from the problem is suicide.

Another thing expressed by participants in this study is that they never wanted to commit suicide or planned suicide before but apparently had the thought that death could be a way out for the problem at hand, this could be explained in the psychoanalytic theory approach to suicide according to Menninger 1996, holiday 2012) that suicide and murder are related to three hopes that are closely related to everyone, those who hope to kill, the hope to be killed and those who wish to die. Unconscious motivation is the basis of the concept of the death instinct. Directly or even not realized that when experiencing great difficulty individuals use the concept of death instinct as an alternative problem solving.

\section{CONCLUSION}

Based on the results of a phenomenological study of the experiences of high school students who carried out suicide attempts in Malang, Indonesia found that the theme of disappointment in parents as the basis of adolescent suicide, harassment from school friends triggers adolescent suicidal thoughts, and adolescents carry out spontaneous suicide attempts without planning. It can be concluded that adolescents can provide a picture of perceptions, causes, methods and ideas of suicide based on experience from the point of view of adolescents who have attempted suicide. 


\section{REFERENCES}

1. Billiocta, Y., Sani, A., \& Jaya, G. D. (2015). Tragis, Siswa-Siswi Ini Bunuh Diri Karena Masalah Percintaan. Retrieved from http://www.merdeka.com/peristiwa/tragissiswa-siswi-ini-bunuh-diri-karena-masalah-per cintaan.html.

2. Cho, Y. B., \& Haslam, N. (2010). Suicidal ideation and distress among immigrant adolescents: The role of acculturation, life stress, and social support. Journal of youth and adolescence, 39(4), 370-379.

3. Farhangdoost, Y. (2010). Determining risk factors and demographic patterns of suicide in Tehran. Polish Psychological Bulletin, 41(2), 52-57.

4. Hanafi, N. (2017). Tumbuh Kembang Remaja (1 ed. Vol. 1).

5. Hassan, A. N., Stuart, E. A., \& De Luca, V. (2016). Childhood maltreatment increases the risk of suicide attempt in schizophrenia. Schizophrenia research, 176(2-3), 572-577.

6. Ibrahim, N., Amit, N., \& Suen, M. W. Y. (2014). Psychological factors as predictors of suicidal ideation among adolescents in Malaysia. PLoS One, 9(10), e110670.

7. Keliat, B. A. (2009). Model Praktik Keperawatan Profesional Jiwa. Jakarta: EGC.

8. Lee, C. T., Chen, V. C., Tan, H. K., Chou, S. Y., Wu, K. H., Chan, C. H., \& Gossop, M. (2013). Suicide and other-cause mortality among heroin users in Taiwan: a prospective study. Addictive behaviors, 38(10), 2619-2623.

9. LoBiondo-Wood, G., \& Haber, J. (2017). Nursing research-e-book: methods and critical appraisal for evidence-based practice. Elsevier Health Sciences.

10. Muhith, A. (2015). Pendidikan Keperawatan Jiwa: Teori dan Aplikasi. Yogyakarta: Andi.

11. Nova, R., Hamid, A. Y. S., \& Daulima, N. H. C. (2019). Family's experience in caring for clients with suicidal risk in indonesia. Enfermería Global, 18(1), 445-463.

12. O'Donnell, S., Meyer, I. H., \& Schwartz, S. (2011). Increased risk of suicide attempts among Black and Latino lesbians, gay men, and bisexuals. American journal of public health, 101(6), 1055-1059.

13. Pisani, A. R., Wyman, P. A., Petrova, M., Schmeelk-Cone, K., Goldston, D. B., Xia, Y., \& Gould, M. S. (2013). Emotion regulation difficulties, youth-adult relationships, and suicide attempts among high school students in underserved communities. Journal of youth and adolescence, 42(6), 807-820.

14. Plemmons, G., Hall, M., Doupnik, S., Gay, J., Brown, C., Browning, W., ... \& Rehm, K. (2018). Hospitalization for suicide ideation or attempt: 20082015. Pediatrics, 141(6), e20172426.

15. Puzo, Q., Qin, P., \& Mehlum, L. (2016). Long-term trends of suicide by choice of method in Norway: a join point regression analysis of data from 1969 to 2012. BMC public health, 16(1), 255.

16. Sadock, B. J., \& Sadock, V. A. (2010). Kaplan and Sadock's pocket handbook of clinical psychiatry. Lippincott Williams \& Wilkins. 
17. Setiyaningrum, E. (2017). Asuhan Kegawatdaruratan Maternitas (Asuhan Kebidanan Patologi). Jakarta: IN MEDIA.

18. Sisask, M. (2012). Conference Scene: Suicidal behaviors: a multidisciplinary issue. Neuropsychiatry, 2(6), 477.

19. Stuart, G. W. (2014). Principles and practice of psychiatric nursing-e-book. Elsevier Health Sciences.

20. Townsend, E. (2007). Suicide terrorists: Are they suicidal?. Suicide and Life-Threatening Behavior, 37(1), 35-49.

21. Tresno, F., Ito, Y., \& Mearns, J. (2012). Self-injurious behavior and suicide attempts among Indonesian college students. Death Studies, 36(7), 627-639.

22. Turecki, G., \& Brent, D. A. (2016). Suicide and Suicidal Behaviour. The Lancet, 387(10024), 1227-1239.

23. Varcarolis, E. M., Halter, M. J., \& Varcarolis, E. M. (2010). Foundations of Psychiatric Mental Health Nursing: A Clinical Approach. St. Louis, MO: Saunders: Elsevier.

24. Videbeck, S., \& Videbeck, S. (2013). Psychiatric-Mental Health Nursing. Lippincott Williams \& Wilkins.

25. Yosep, I., \& Sutini, T. (2014). Buku Ajar Keperawatan Jiwa. Bandung: Refika Aditama. 